\title{
Repair of soft tissue defects of the fingers with medial plantar venous flap
}

\author{
(D) /in Yang ${ }^{1}$ \\ Yongfeng Tang ${ }^{1}$ \\ Huabin $\mathrm{He}^{1}$ \\ Shangjun Fu ${ }^{1}$
}

1. Department of hand and foot surgery, Yiwu Central Hospital, Jiangdong Road 699\#, Yiwu city, Zhejiang province, China

http://dx.doi.org/10.1590/1806-9282.64.06.501

\section{SUMMARY}

OBJECTIVE: To report the surgical procedures and efficacy of using medial plantar venous flap for the repair of soft tissue defects of the fingers.

Methods: From March 2010 to April 2012, medial plantar venous flaps were harvested to repair the wounds of 31 fingers in 29 cases. Among them, there were 13 middle fingers with defects at the tips in 11 cases, 7 fingers with defects in the dorsal part in 7 cases, and 11 fingers with defects in the finger pulp in 11 cases. The size of the defects ranged from $1.2 \mathrm{~cm} \times 1.5 \mathrm{~cm}$ to $2.5 \mathrm{~cm} \times 3.5 \mathrm{~cm}$. Medial plantar venous flaps of $1.5 \mathrm{~cm} \times 2 \mathrm{~cm}-3 \times 4 \mathrm{~cm}$ were harvested. Full-thickness skin grafts were adopted for the donor areas.

RESULTS: All 31 flaps survived, except for 1 flap with arterial crisis and 2 cases with venous crisis. These conditions were timely corrected by secondary anastomosis of artery and vein and the flaps survived. The wounds and the donor areas achieved healing by the first intention. All grafted skins survived. Postoperative follow-up was conducted for 26 fingers in 24 cases for 4- 12 months, excluding 5 cases with lost follow-up. The dorsal part of the damaged fingers had normal morphology, and the skin color and texture were similar to those of the normal skin. After the repair of defects in the fingertip and pulp, fingerprints appeared, and the protective sensation was restored.

CONCLUSION: The soft tissue defects of the fingers can be satisfactorily repaired with medial plantar venous flap, and little damage is caused to the donor area. This method is proven effective for the repair of soft tissue defects of the fingers.

KEYWORDS: Finger injuries. Finger/surgery. Surgical flaps. Reconstructive surgical procedures/methods.

Soft-tissue defects of the fingers are very common in the clinical practice and can be associated with the exposure of deep tendons and bone tissues, which adds difficulty to the surgery. Nakayama et al. ${ }^{1}$ (1981) were the first to successfully establish the model of the arterialized venous flap, after which the venous flap has found extensive applications. We repaired soft tissue defects in 31 fingers of 29 cases using the medial plantar venous flaps, from March 2010 to April 2012. The patients generally achieved satisfactory outcomes.

\section{MATERIALS AND METHOD}

\section{Subjects}

Thirty-one injured fingers in 29 cases were selected (20 males, 11 females, aged 19-49 years, with an average age of 27). Among them, there were 13 middle fingers with defects at the tips in 11 cases, 7 fingers with defects in the dorsal part in 7 cases, and 11 fingers with defects in the finger pulp in 11 cases. There were 1 thumb, 15 index fingers, 12 middle fingers and 3 ring fingers wounded. As to the reasons of injury, 16 were caused by mechanical crush, 6 were

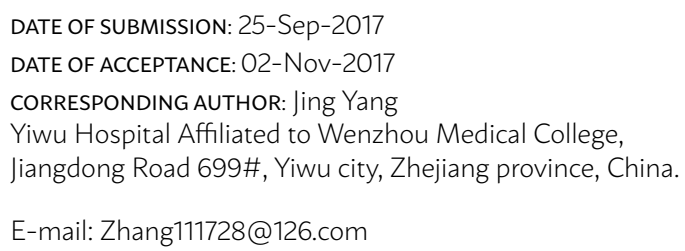


hot-crush injuries, 6 electric saw accidents and 1 infection after trauma of the dorsal part. The size of the defects varied from $1.2 \mathrm{~cm} \times 1.5 \mathrm{~cm}$ to $2.5 \mathrm{~cm} \times 3.5 \mathrm{~cm}$.

\section{Procedures}

1. Repair of finger palmar skin defects with medial plantar venous flap: Radical debridement was performed conventionally. The medial plantar venous flap was designed based on the conditions of the wound. The dorsalis pedis artery with a parallel-oblique proximal orientation was located. Depending on the specific needs, 1-2 superficial veins with the diameter comparable to the vessel to be anastomosed were chosen as the trunk veins of the flap. The flap was designed based on the anatomical relationship between the wound surface and the defective artery. The skin and the superficial fascia were cut open along the markers. The flap was deeply dissociated at the trunk veins. The flap only carried the skin and a thin layer of subcutaneous tis-

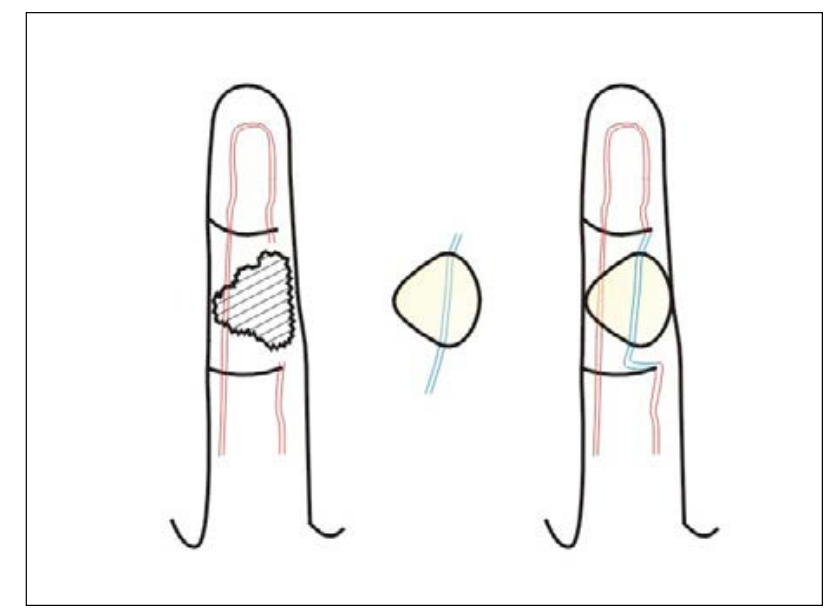

FIG. 1

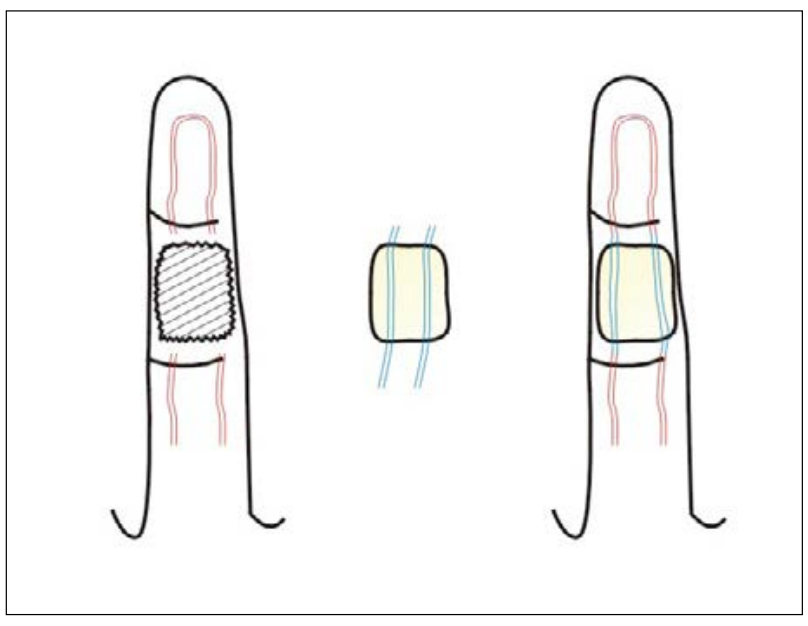

FIG. 2

Foundation: Scientific research program of Yiwu City (12-3-23) Affiliation: Hand and foot surgery, Affiliated Yiwu Hospital of Zhejiang University.

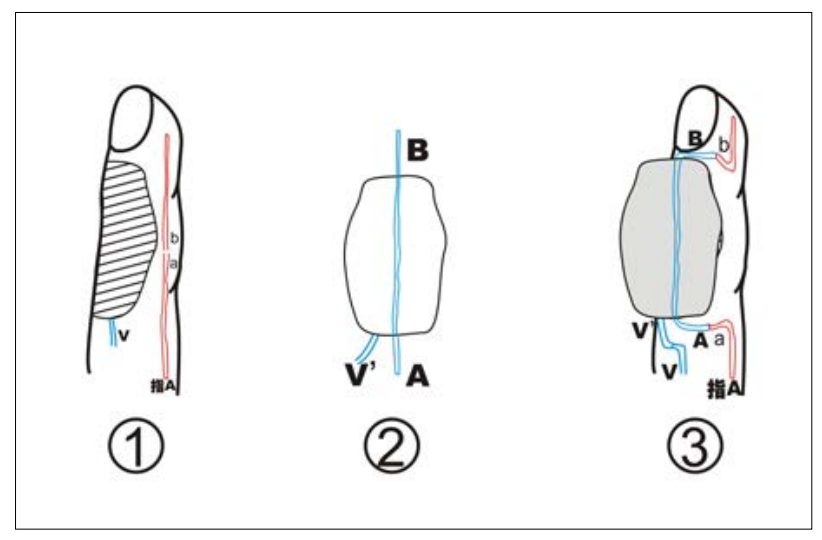

FIG. 3

sue with the veins. There was no need to expose the trunk vein when dissociating the flap. The length of the vessel to be anastomosed should be longer than that of the flap. The flap was then grafted to the palmar skin defect. The wound surface was repaired while performing reverse bridging of the trunk vein to the artery. The direction of venous blood flow in the flap should be parallel with that of the venous valve (see Fig. 1 and 2).

2. Repair of defects in the dorsal part of the finger with medial plantar venous flap: Radical debridement was performed conventionally. The medial plantar venous flap was designed based on the conditions of the wound. The dorsalis pedis artery with a parallel-oblique proximal orientation was located. Depending on the specific needs, 1 superficial vein with the diameter comparable to the vessel to be anastomosed was chosen as the trunk vein of the flap. The flap was designed based on the anatomical relationship between the wound surface and the defective artery. The skin was cut open along the markers. The flap was deeply dissociated at the trunk vein. The flap only carried the skin and a thin layer of subcutaneous tissue with the vein. There was no need to expose the trunk vein when dissociating the flap. The length of the vessel to be anastomosed should be longer than that of the flap. One of two additional veins were preserved at the proximal end of the flap. The flap was then grafted to the wound surface in the dorsal part of the finger. The proper palmar digital arteries were dissociated and severed in the middle part of the wound surface. Anastomosis was performed between the proximal artery and the proximal trunk vein of the flap and between the distal artery and the distal trunk vein, so as to establish the proper palmar digital arteries. The spare vein of 
the proximal flap was anastomosed to the proximal vein of the wound surface in order to ensure the venous reflux of the flap (see Fig. 3).

3. Repair of defects in the fingertip with medial plantar venous flap: Radical debridement was performed conventionally. The medial plantar venous flap was designed based on the conditions of the wound. The dorsalis pedis artery with a parallel-oblique proximal orientation was located. Depending on the specific needs, 1 superficial vein with the diameter comparable to the vessel to be anastomosed was chosen as the trunk vein of the flap. Alternatively, two veins showing an $\mathrm{H}$-shaped orientation were chosen as the trunk veins of the flap. The flap was designed based on the anatomical relationship between the wound surface and the defective artery. When the defect was small, the venous flap was harvested from a single vessel; if the defect was large, two venous flaps with an $\mathrm{H}$-shaped orientation were harvested. The skin was cut open along the markers. The flap was deeply dissociated at the trunk vein. The flap only carried the skin and a thin layer of subcutaneous tissue with the vein. There was no need to expose the trunk vein when dissociating the flap.

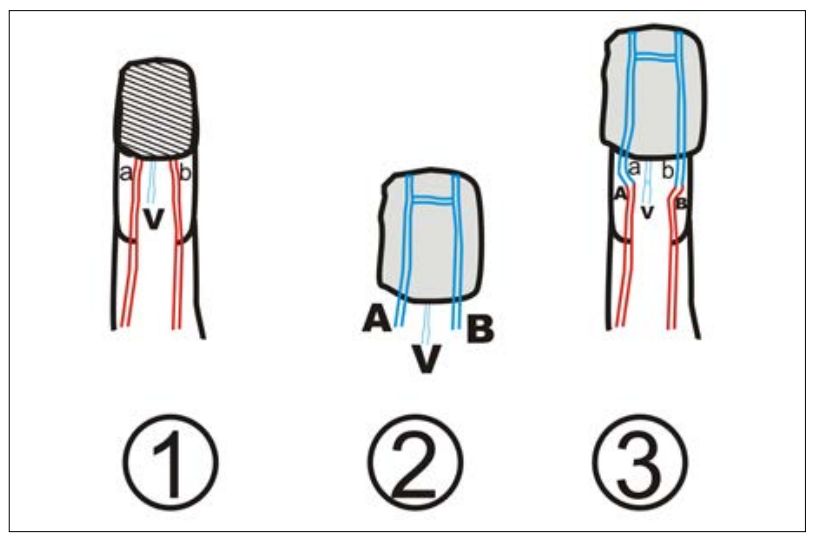

FIG. 4

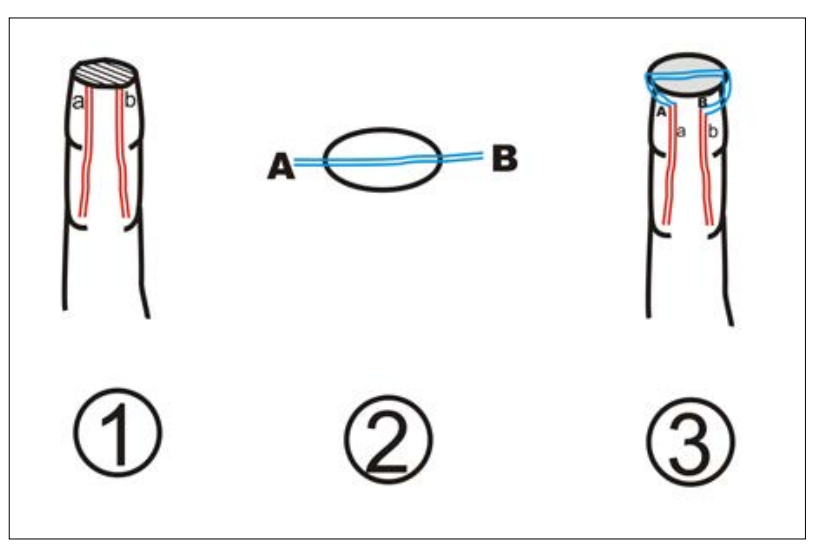

FIG. 5
The length of the vessel to be anastomosed should be longer than that of the flap. The flap was grafted to the wound surface. When a single venous flap was used to repair the wound surface, the proximal and distal ends of the veins were anastomosed to bilateral proper palmar digital arteries to form an archshaped loop of the arteries. When two venous flaps with an $\mathrm{H}$-shaped orientation were used to repair the wound surface, the distal ends of the two veins were ligated, while the proximal ends were anastomosed to the proper palmar digital arteries. If the flap was large, one palmar digital vein was anastomosed to ensure the survival of the flap (see Fig. 4 and 5).

\section{RESULTS}

All 31 flaps survived. The flaps turned from light red to rosy 5-10 minutes after the blood was let through. The capillaries showed a normal response. The flaps were rosy 1-3 days after the operation, with normal response of capillaries but aggravated swelling. The flap color turned into dark red 4-7 days after surgery and the swelling persisted. The swelling receded later. The venous flaps were larger in size for 5 cases that had tension vesicles at 3 days after the operation, which disappeared spontaneously at 8-10 days. The other cases had no vesicles. One case had an arterial crisis and 2 cases had venous crisis. These cases received secondary anastomosis and embolism of the artery and vein, and all flaps survived. The wounds and the donor areas achieved healing by first intension, and the grafted skins survived. Twenty-four cases were followed up for 4-12 months, excluding those with lost follow-up. The dorsal part of the damaged fingers had normal morphology, and the skin color and texture were similar to those of the normal skin. After the repair of defects in the fingertip and pulp, fingerprints appeared, and the protective sensation was restored.

\section{TYPICAL CASES \\ Case 1}

The 30-year-old male patient was injured in the right index finger by mechanical crush, which led to the fracture of the proximal phalanx of the right index finger. There was a $1.5 \mathrm{~cm} \times 2.5 \mathrm{~cm}$ soft tissue defect in the middle segment on the palmar side. The bilateral proper palmar digital arteries 
ruptured. After emergency debridement, reduction fixation of the bone fracture was performed. A medial plantar venous flap of $2 \mathrm{~cm} \times 3 \mathrm{~cm}$ was harvested. The two trunk veins of the flap were bridged to bilateral proper palmar digital arteries. A full-thickness skin graft was harvested to repair the skin defect. The flap survived, and the wound and donor area achieved healing by first intention. The skin graft survived. The color and texture of the flap were similar to those of the normal skin at the eighth month of follow-up. The patient was satisfied with the appearance of the operated site.
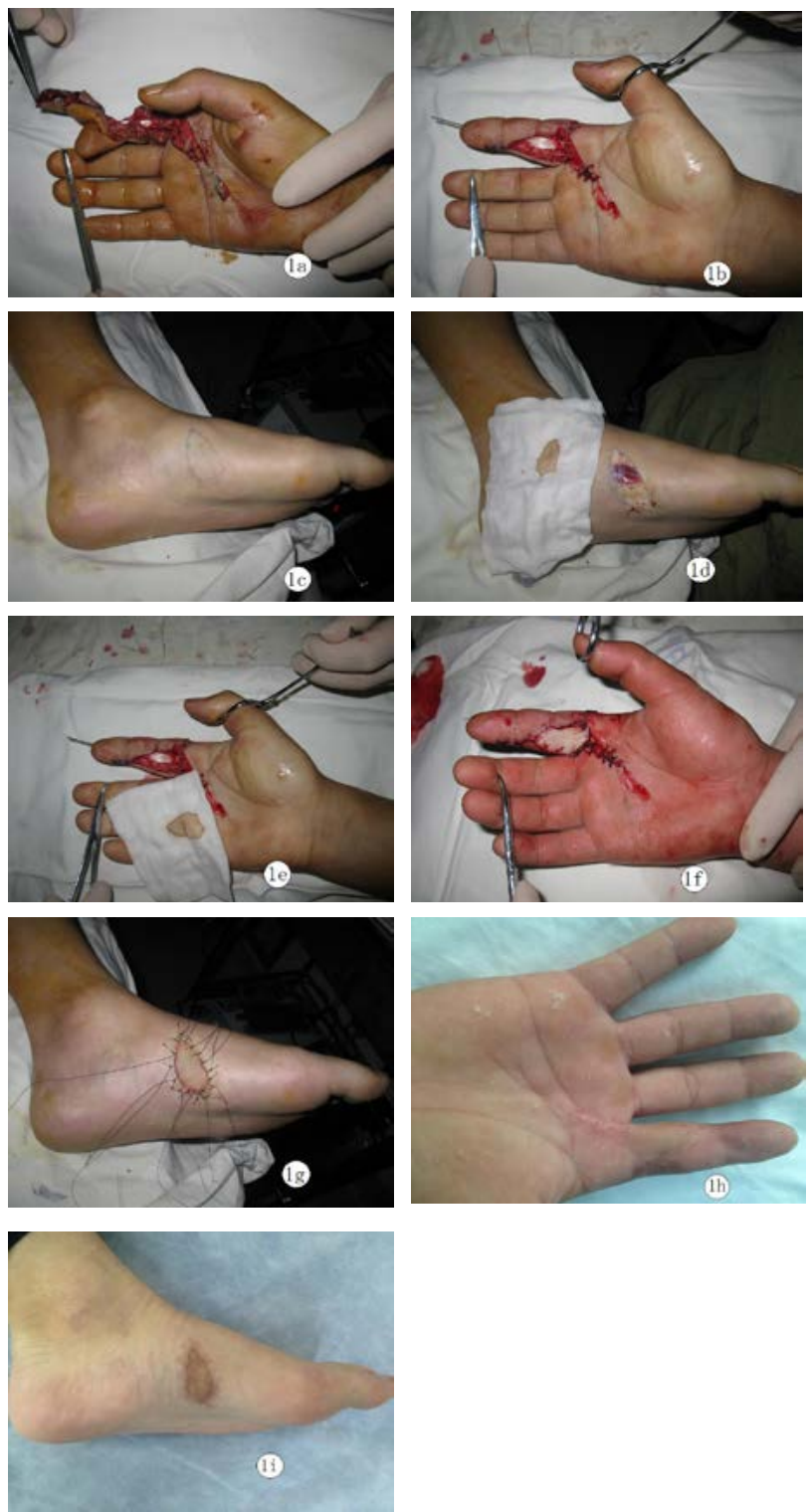

CASE 1. Fig. 1 a,b. Wound surface in the right index finger after the debridement; c. Design of flap from the donor area; d,e. Harvesting and transplantation of the flap; f. Flap immediately after the surgery; g. Skin graft from the donor area; $h$. Flap at 8 months after the surgery; i. Donor area at 8 months after the surgery.
The skin graft was normal, and no adverse impact was generated on the left foot mobility and weight bearing capacity.

\section{Case 2}

The 39-year-old female patient was injured in the dorsal part of the right index finger with third-degree scalding due to crushing by a stamping machine. After emergency debridement, a wound of $2.0 \mathrm{~cm}$ $\times 4.0 \mathrm{~cm}$ was found in the dorsal part of the right index finger, with partial damage to the extensor tendon. In addition, the extensor tendon and middle phalanx were exposed, with skin defects of $0.5 \mathrm{~cm} \times$ $1.0 \mathrm{~cm}$ and $0.5 \mathrm{~cm} \times 0.6 \mathrm{~cm}$ in the proximal and distal cross striations at the palmar side, respectively. In the dorsal part, there was a wound of $8.0 \mathrm{~cm} \times 2.0 \mathrm{~cm}$ with moderately good subcutaneous tissues. The necrotic extensor tendon was removed, and a $2.5 \mathrm{~cm}$ $\times 4.5 \mathrm{~cm}$ medial plantar venous flap was harvested from the right foot. The free proper palmar digital arteries were harvested from the ulnar side and severed in the middle of the wound surface. Anastomosis was performed between the proximal and distal ends of arteries and the proximal and distal ends of
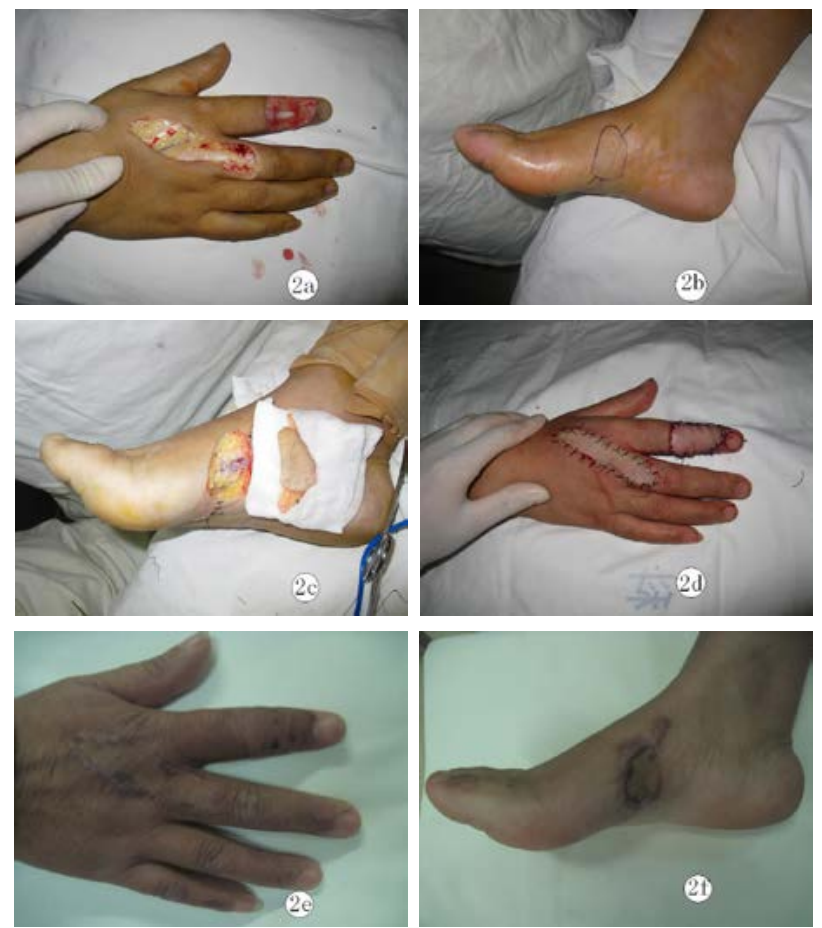

CASE 2. Fig. 2 a. Wound surface in the right index finger before surgery; b. Design of flap from the donor area; $c$. Immediately after the flap harvesting; $d$. Flap immediately after the surgery; e. Flap at 6 months after the surgery; f. Donor area at 6 months after the surgery. 
trunk veins of the flap, respectively. The spare distal vein of the flap was anastomosed to the vein in the dorsal part. A full-thickness skin graft was harvested from the donor area. Other parts of the wound were repaired with an ilioinguinal full-thickness skin graft. The flap survived, and the wound and donor area achieved healing by first intention. During the 6-month follow-up, the color and texture of the flap were similar to those of the normal skin. The patient was satisfied with the appearance of the operated site. The skin graft was normal, and no adverse impact was generated on the right foot mobility and weight bearing capacity.

\section{Case 3}

The 43-year-old female patient lost the tips of the left thumb and left middle finger because of a mechanical crush. After radical debridement, an island-shaped flap was used to repair the defect in the left middle finger, and the medial tarsal flap for the
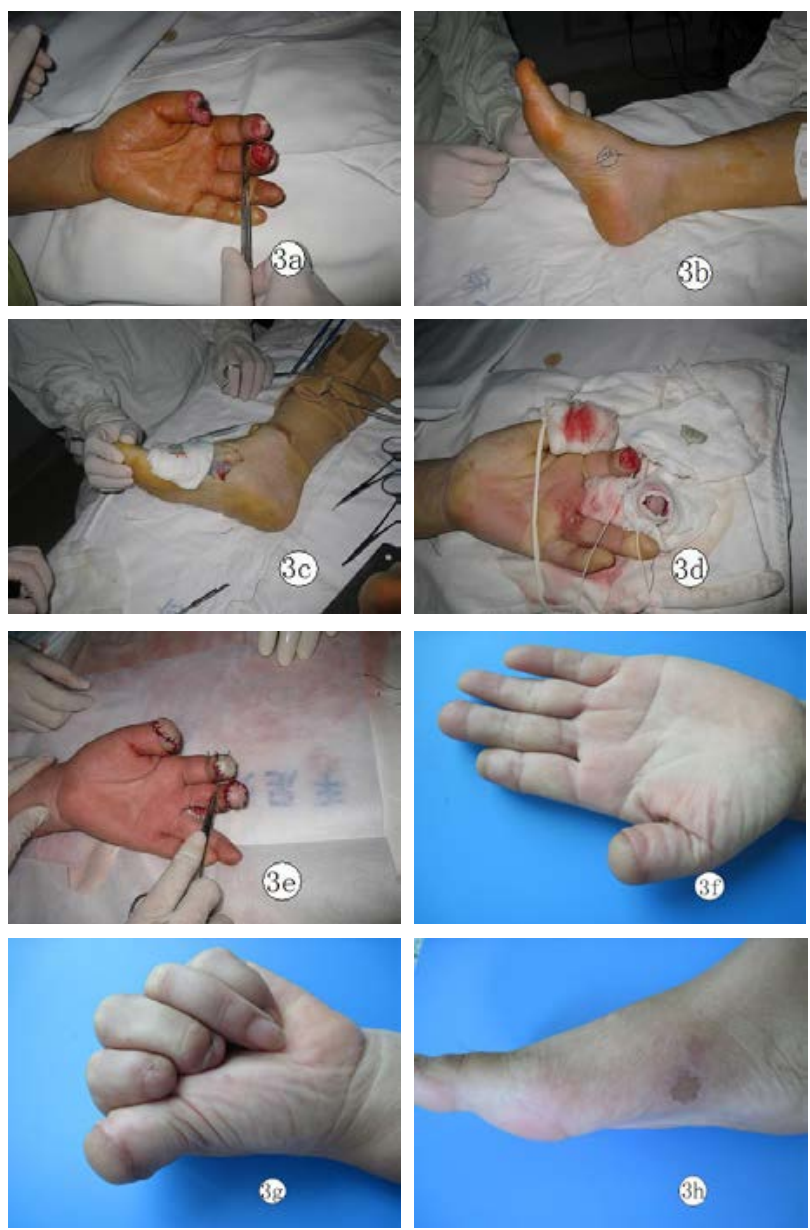

CASE 3. Fig. 3 a. Before the surgery; b. Design of the flap from the donor area; c,d. Flap harvesting and transplantation; e. Flap immediately after the surgery; f,g. Flap at 3 months after the surgery; i. Donor area at 3 months after the surgery left thumb. The defect in the left index finger was about $1.5 \mathrm{~cm} \times 1.5 \mathrm{~cm}$ and was repaired with a $2 \mathrm{~cm} \times$ $2 \mathrm{~cm}$ medial plantar venous flap from the right foot. The flap carried one trunk vein, and the proximal and distal ends of the vein were anastomosed to the bilateral proper palmar digital arteries, respectively. A full-thickness skin graft was harvested from the donor area. The flap survived, and the wound and donor area achieved healing by first intention. The skin graft survived. The color and texture of the flap were similar to those of the normal skin at 3 months after surgery. The patient was satisfied with the appearance of the operated site. The two-point discrimination of the flap was $10 \mathrm{~mm}$.

\section{Case 4}

The 45-year-old male patient lost the tips of the left index finger and middle finger due to mechanical crushing. The defect was about $1.8 \mathrm{~cm} \times 2.5 \mathrm{~cm}$ in the left index finger and $2 \mathrm{~cm} \times 3 \mathrm{~cm}$ in the left middle
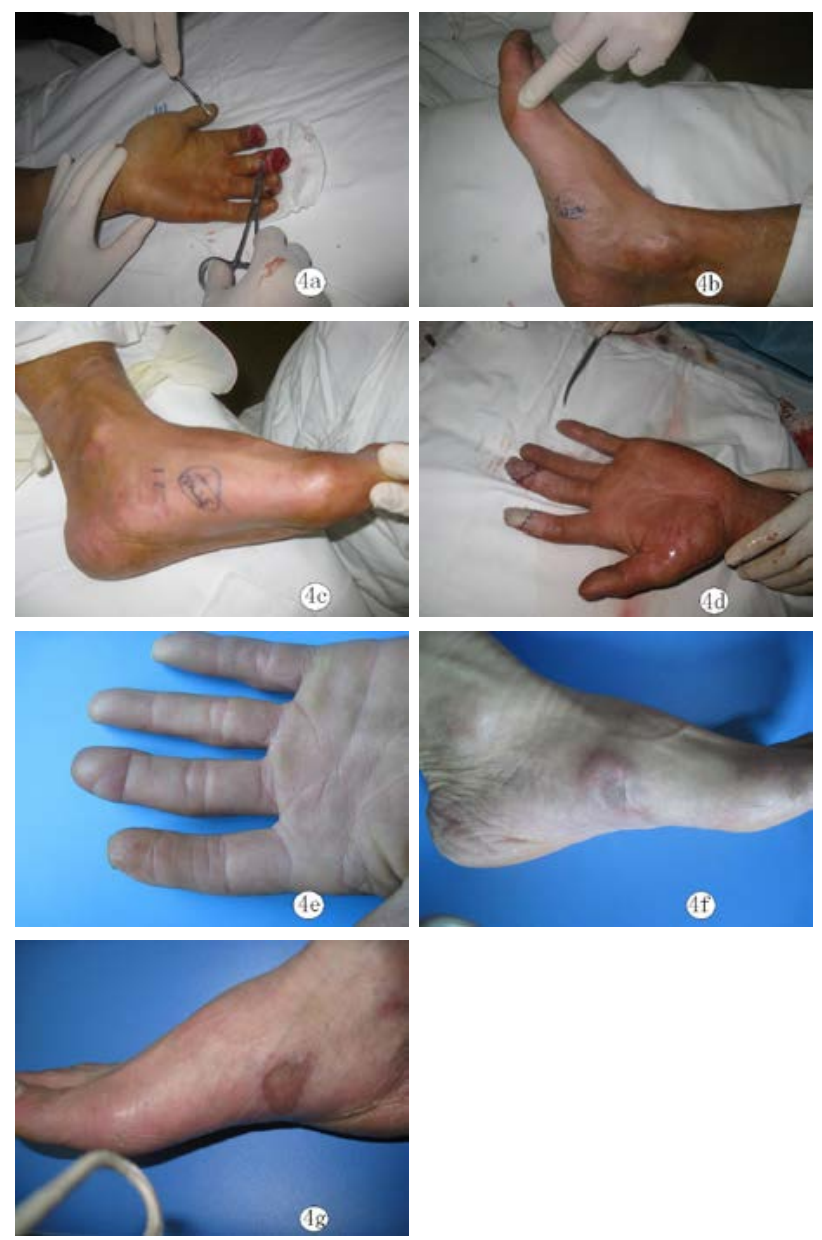

CASE 4. Fig. 4 a. Before the surgery; b,c. Design of the flap from the donor area; $d$. Flap immediately after the surgery; e. Flap at 6 months after the surgery; $f, g$. Donor area at 6 months after the surgery 
finger. The distal phalanx was exposed with defects of the nail bed in the left middle finger. After radical debridement, a $2.5 \mathrm{~cm} \times 3 \mathrm{~cm}$ medial plantar venous flap was harvested from the left foot to repair the defect in the left index finger, and a thin layer of nail bed from the right foot thumb for the left middle finger. The wound surface was repaired with a $2.5 \mathrm{~cm} \times$ $3.5 \mathrm{~cm}$ medial plantar venous flap from the right foot. The two flaps carried two veins with H-shaped orientation, respectively. The distal ends of the two veins were ligated, while the proximal ends were anastomosed to the bilateral proper palmar digital arteries, respectively. One palmar digital vein was anastomosed. A full-thickness skin graft was harvested from the donor area. The flap and the transplanted nail bed survived. The wound and the donor area achieved healing by first intention. The skin graft survived. At 6 months after surgery, the color and texture of the flap were similar to those of the normal skin. The patient was satisfied with the appearance of the operated site. The two-point discrimination of the flap was $8 \mathrm{~mm}$.

\section{DISCUSSION}

\section{Background}

The repair of soft tissue defects of the fingers using miniature flaps has found extensive applications along with the development of the microsurgical technique. The flaps commonly used for the repair include free fibular skin flap of the foot thumb, tibial flap of the second toe, free flap based on superior-wrist cutaneous branch of the ulnar artery, interosseous dorsal artery flap and free perforator artery of the shank..$^{2-6}$ The size of the fibular skin flap of the foot thumb and tibial flap of the second toe should not be too large to prevent damage to the toes, and the flaps may sometimes die. Free flap based on a superior-wrist cutaneous branch of the ulnar artery and interosseous dorsal artery flap have the defect of a small diameter of the vessels and the donor area is less hidden, which affects the appearance of the forearm. The free perforator artery of the shank is larger in size, and the finger morphology and recovery of sensation may be poor after the repair. The above flaps are not fit for repairing the defects in bilateral proper palmar digital arteries and the wound surface simultaneously. In that case, the forearm venous flap is usually used. ${ }^{7}$ Conventional venous flaps may have the defects of unstable blood supply, low survival, pigmentation and hard texture. ${ }^{8,9}$ With the rising of people's living standard, the requirements on the repair aesthetics and functional recovery in hand injuries are also rising. There is also the need for harvesting flaps from hidden donor areas. According to $\mathrm{Gu},{ }^{10}$ since the demand for repair aesthetics and functional recovery of hands is higher, it is better to harvest flaps from other positions, if possible. The medial plantar skin has a similar structure and texture as the palmar digital skin and therefore, it is fit for restoring the structure and morphology of the fingers. The fingerprints can be restored using the medial plantar skin, which is wear resistant, less slippery and conducive to hold objects. Therefore, the medial plantar region is an ideal donor area for the repair of soft tissue defects of fingers.

2. Survival mechanism of the arterialized venous flap (AVF): The survival mechanism of flaps is mainly related to blood circulation within the flap (balance between inflow and outflow). As to the survival AVF, Ji et al. ${ }^{11}$ proposed 3 pathways for the AVF to acquire nutrients, in 1982: (1) The arterial blood enters the arterioles by the anastomosis between the venules and arterioles and then into the capillary network, where physiological perfusion takes place; (2) The arterial blood directly flows backward into the capillary network via the venules, where non-physiological perfusion takes place; (3) Blood circulation is formed between the flap and the normal surrounding tissues after some time; thus the blood is supplied to the flap. According to Imanishi et al. ${ }^{12}$, communicating branches exist between the microvenous connection, accompanying veins and superficial venous network as well as between the microvenous connection, accompanying veins of the artery perforator, and paraneural nexus. Venous valves are usually found within the communicating branches. However, the venous valves are thin and there is the risk of reverse flow when the venous pressure increases. Chen et al. ${ }^{13}$ proposed a microcirculation pattern important for the early survival of the flap: the blood flow circulates from the thin veins to the communicating branches and then back to the thin veins. In the later stages, the new blood vessels at the basal part of the receptor area and the invading ones at the flap margins provide stable blood supply to the flap. Xia et al. ${ }^{14}$ found through experimentation that in the early stage of venous flap transplantation, the anastomotic branches between the artery and vein rarely open; no blood flows through the arterioles, or the ar- 
terioles were obstructed. Under the microcirculation microscope, a large number of anastomotic branches between the veins open. Therefore, even in the presence of local clogging, collateral circulation can be established to bypass the venous flaps or thrombi and to supply blood to the distal flap. This is regarded as the survival mechanism of AVF, which can be briefly described as the circulation of venules $\rightarrow$ microveins $\rightarrow$ microveins $\rightarrow$ venules. Liu et al. ${ }^{15}$ proposed the pathway of blood supply to AVF based on clinical trials: arterial blood $\longrightarrow$ trunk vein $\longrightarrow$ venules $\rightarrow$ microveins $\longrightarrow$ capillary network (substance exchange) $\rightarrow$ microveins $\rightarrow$ venules $\rightarrow$ trunk vein $\rightarrow$ reflux. Therefore, the survival mechanism of AVF mainly relies on the extensive communicating branches between the microveins, venules and trunk vein, with an effective blood circulation to ensure flap survival.

3. Postoperative changes of flap color and causes of the swelling: In the early days after flap transplantation (1-7d), microcirculation is not yet formed between the flap and the receptor area. Since the blood is supplied to the flap by the arteries and the number of open microvenous circulations increases, the perfusion of the flap increases. That means more blood flows into the flap than out of it. As a consequence, the flap is dark-red colored and swollen. After $7 \mathrm{~d}$, the swelling gradually recedes with the establishment of local microcirculation, and the flap color changes back to normal. The flap survives, and the venous arterialization is finished. When the venous flap is small, there are fewer vascular networks in it and the perfusion of the flap is low. It is easier to establish a microcirculation between the flap and the wound surface to promote reflux. Therefore, smaller flaps are more likely to survive with a lower possibility of vesicle formation. But in larger flaps, there are more vascular networks and the perfusion of the flap is large. With lower blood reflux, vesicles are more likely to appear.

4. Advantages of the medial plantar venous flap: The survival of venous flaps depends on the perfusion of the capillaries ${ }^{16}$, which in turn is related to the number of capillaries. According to Xia et al. ${ }^{14}$, abundant venous networks are the histomorphological basis for the survival of AVF. Moretti et al. (1959) believed that the number of superficial dermal microvessels is proportional to the skin thickness. The palmar and plantar skins are thick and have a higher capillary density in the papillary layer. This feature can increase the flap survival. The medial plantar veins have a thicker wall than the forearm venous flap and therefore are easier to be arterialized. The medial plantar veins have several anastomotic branches, and the venous return of the flap is more satisfactory, thus increasing flap survival. Sun et al. ${ }^{17}$ found through clinical practice that medial plantar venous flap had a better blood supply, a higher survival rate and better quality of soft tissues after the repair than the venous flaps harvested from other positions.

5. Strengths and shortcoming of the flaps: Plantar skin has similar structure and texture as the finger skin and therefore is applicable to the repair of soft tissue defects on the fingers. The plantar skin is wear resistant, less slippery and has quick sensation. ${ }^{18}$ The medial plantar veins have constant anatomy and occur in large quantities; they can be harvested with high availability and flexibility. Moreover, their diameter is similar to that of the proper palmar digital arteries, which makes anastomosis easier. For the repair of a defect in the proper palmar digital arteries, bridging of the blood vessels can be performed to restore blood supply to the fingers. The donor site of the medial plantar venous flap is hidden and does not bear weight. Less damage is caused to this donor site. However, the area of the medial plantar venous flap should not be too large, and the surgeons are expected to be skillful in the anastomosis of the blood vessels.

6. Matters deserving attention during surgery: (1) The venous flaps tend to swell immediately after surgery and then shrivel in later stage, so they should be slightly larger than the wound surface; (2) The orientation of the trunk vein should be marked, and longer proximal and distal ends of the trunk vein should be preserved to facilitate the anastomosis with the blood vessels in the receptor site. The free length of the proper palmar digital arteries in the receptor site should be sufficiently long to facilitate the anastomosis with the blood vessels and to avoid their reversal. In this way, the trunk vein can be enveloped within the flap as much as possible to increase the perfusion of the flap; (3) When the flap is larger, the returning veins should be anastomosed to improve the reflux to the flap veins. This is because improving the venous reflux is very important for ensuring the early survival of the flaps; ${ }^{19}$ (4) Postoperative placement of the drainage tube: Considering the obstructed venous reflux and postoperative exudation of the flap, a drainage tube can be inserted to reduce hematoma and infection and to facilitate tissue healing and blood supply reconstruction. 


\section{RESUMO}

OBJETIVO: Relatar os procedimentos cirúrgicos e a eficácia do uso de retalhos plantares mediais venosos para reparo de defeitos de tecidos moles dos dedos.

METODOLOGIA: De março de 2010 a abril de 2012, foram colhidos retalhos plantares mediais venosos para reparar ferimentos de 31 dedos em 29 casos. Entre eles, 13 dedos médios com defeitos nas pontas em 11 casos, 7 dedos com defeitos na parte dorsal em 7 casos e 11 dedos com defeitos na polpa digital em 11 casos. O tamanho dos defeitos variava de $1,2 \mathrm{~cm} \times 1,5 \mathrm{~cm}$ a $2,5 \mathrm{~cm} \times 3,5 \mathrm{~cm}$. Foram colhidos retalhos plantares mediais venosos de $1,5 \mathrm{~cm} \times 2 \mathrm{~cm}$ a $3 \mathrm{~cm} \times 4 \mathrm{~cm}$. Foram adotados enxertos de pele de espessura total na área doadora.

RESULTADOS: Todos os 31 retalhos sobreviveram, com exceção de 1 retalho com crise arterial e 2 casos com crise venosa. Esses problemas foram corrigidos a tempo com anastomoses secundárias das artérias e veias e os retalhos sobreviveram. Os ferimentos e áreas doadoras atingiram cicatrização por primeira intenção. Todos os enxertos de pele sobreviveram. Foi realizado acompanhamento pós-operatório em de 26 dedos em 24 casos por 4 a 12 meses, sendo que dos casos tratados 5 não tiveram acompanhamento. As partes dorsais dos dedos lesionados apresentaram morfologia normal, com cor e textura da pele muito similares a da pele normal. Após o reparo dos defeitos nas pontas e polpas digitais, impressões digitais apareceram e a sensação protetora foi restaurada.

CONCLUSÃO: Os defeitos de tecido mole dos dedos podem ser reparados de forma satisfatória com retalhos plantares mediais venosos, com poucos danos à área doadora. Este método mostrou se eficaz para o reparo de defeitos de tecido mole dos dedos.

PALAVRAS-ChaVe: Lesões nos dedos. Cirurgia/dedos. Retalhos cirúrgicos. Procedimentos/métodos cirúrgicos reconstrutivos.

\section{REFERENCES}

1. Nakayama $Y$, Soeda $S$, Kasai $Y$. Flap nourished by arterial inflow through the venous system: an experimental investigation. Plast Reconstr Surg. 1981;67(3):328-34.

2. Zeng ZC, Li P, Ji ZY. Repair of finger skin defects with dorsal fibular flap of the great toe. Chinese J Microsurg. 2010;33(6):496-7.

3. Gu JX, Liu HJ, Zhang NC, et al. Repair the palmar soft tissue defects of the fingers with free miniature flap of the toe. Chinese | Hand Surg. 2011;27(6):371-2

4. Wang YB, Wang ZT, Miao BLH. Transplanting the flap pedicled with the ascending branch of the supracarpal cutaneous branch of ulnar artery to repair skin defect on fingers. Chinese J Microsurg. 2006;29(5):344-6.

5. Hu HL, Wang $X$, Chen $H$. Repair of soft tissue defects of the fingers with free perforator flap of posterior interosseous artery of forearm. Chinese Hand Surg. 2011;27(3):189-90.

6. Mei LB, Xu YQ, Zhu YL. Repair of finger skin defects with free perforator flap of the peroneal artery. Chinese J Orthopaedic Trauma. 2012;14(7):634-5.

7. Zeng ZC, Li P, Ji ZY. Application of arterialized venous flap in complex finger trauma. Chinese J Orthopaedic Trauma. 2006;8(11):1080-1.

8. Yang WD, Tong ZH, Sun HW. Repair of soft tissue defects of fingers with arterialized venous flap. Chinese J Reparative Reconstructive Surg. 2007;21(6):656-7.

9. Yan H, Brooks D, Ladner R, Jackson WD, Gao W, Angel MF. Arterialized venous flaps: a review of the literature. Microsurgery. 2010;30(6):472-8.

10. Gu YD. Principles of repair of finger skin defects. Chinese J Hand Surg 28(3):130.
11. Ji SR, Cheng XX. lia SL. Transplantation of free reticulation venous flap: a report of animal experiment. Traumatology \& Orthopedics Quarterly. 1982;3(1):16.

12. Imanishi $\mathrm{N}$, Nakajima $\mathrm{H}$, Aiso $\mathrm{S}$. A radiographic perfusion study of the cephalic venous flap. Plast Reconstr Surg. 1996;97(2):408-12.

13. Chen JM, Liang J, Chen ZG. Experimental study on forms of microcirculation of arterialized venous flap in rabbits. Zhongguo Xiu Fu Chong Jian Wai Ke Za Zhi. 2002;16(3):170-2

14. Xia YJ, Tian X. Experimental study of the survival mechanism of non-physiological blood perfusion of arterialized venous flap. Qingdao University College of Medical Science. 2003;39(2):127-9.

15. Liu XG, Zhang MS, Yang |G. Clinical application of improved free arterialized venous flap. Chinese J Hand Surg. 2007;23(4):224-5.

16. Lin $Y T$, Henry SL, Lin CH, Lee HY, Lin WN, Lin CH, et al. The shunt-restricted arterialized venous flap for hand/digit reconstruction: enhanced perfusion, decreased congestion, and improved reliability. I Trauma. 2010;69(2):399-404.

17. Sun WH, Wang ZT, Qiu SQ. Repair of palmar soft tissue defects with the medial plantar venous flap. Chinese J Repar Reconstr Surg. 2010;24(1):50-2.

18. Wang CY, Chai YM, Cheng TQ. Applied anatomy and clinical application of medialis pedis perforator flap in anastomosed vessels. Chinese | Microsurg. 2010;1:3-5.

19. Li RH, Kan SL, Li MX. Emergency repair of finger soft tissue defects with arterialized venous flap. Chinese J Repar Reconstr Surg. 2008;22(7):797-9. 